\title{
Two Left Feet
}

\section{Dancing in Academe to the Rhythms of Neoliberal Discourse}

\author{
COLleEn McGLOIN AND \\ JEANNETTE STIRLING \\ UNIVERSITY OF WOLLONGONG
}

-INTRODUCTION

Notions of culture, cultural diversity and cultural safety have again come to the centre of higher education awareness in Australia. The Education Services for Overseas Students (ESOS) Act 2000 ensures that Australian universities have a legal and pedagogical obligation to effectively support the language and learning requirements of international students. The Final Report on the 2008 Review of Australian Higher Education (hereafter referred to as the Bradley Report) recommends a range of initiatives geared to make Australian universities more competitive in the global market place while also becoming more accessible for Indigenous students, domestic students of 'low socio-economic status', and other identified equity groups. ${ }^{1}$ At the frontline of all these initiatives, both proposed and implemented, are those who design, coordinate and teach curricula in the multicultural environs of our university classrooms. 
The question we explore in this essay is how to respond substantively-and ethically-to the sorts of initiatives sketched above. How do we best meet the needs of all our students while stepping through our roles to the sometimes discordant rhythms that can resonate through the hallways of Australian universities? We engage this question through discussion of one of the more recent initiatives in Australian higher education: the move to introduce Indigenous cultural competence into national curricula. Through the following discussion we examine current models of cultural competence and consider some of the conceptual and policy frameworks shaping its implementation. We also contemplate, in our critical awareness of neoliberal discourse's endorsement of cultural competence, how, as non-Indigenous academics, we continue to negotiate a speaking position from within teaching contexts to which, culturally, we do not belong, yet are ethically committed. In an effort to move beyond the current orthodoxy of cultural competence, we want to begin a conversation about speaking positions that refuses to disarticulate culture from gender, age, class, sexuality and other considerations that inscribe subjectivity. Our aim is to understand the underpinnings of 'cultural competence' as a contemporary preoccupation and to unmask the relations of power that give rise to its discursive authority.

We situate this article within the current debates surrounding cultural competence and the Bradley Report while drawing from various theoretical insights into what might constitute an ethics of mindfulness towards students from diverse cultural backgrounds. We raise questions about whether, or how, models of cultural competence can be useful, or if such programs are always constrained by the institutional relations of power that organise their implementation. We have found that a neat and systematic review of the existing literature is beyond the focus of this article: the iterations of cultural competence are diverse, often discipline specific and speak to multiple foci. Rather, we examine the implications of the policy as it currently stands. Our discussion is therefore dialogic and we deploy the metaphor of dance to choreograph our experiences of teaching which underscore our concerns about cultural competence programs in their current formations.

Navigating the culturally diverse terrain of today's university teaching and learning spaces is complex. It is particularly so in a climate where class sizes are increasing and many academics are being required to do more with fewer resources 
while simultaneously remaining innovative in their teaching practices and productive in research output. To again draw on the metaphor of dance, the complex choreography of the classroom should, at least notionally, aspire to some sort of synchronous and meaningful relationship between words and acts, policy and practice: between conceptualisation of the required steps and execution. The rhythms of these choreographies should also draw students, all students, into the challenges, excitement and creative pleasures of learning. This article's metaphorical reference point is by no means a trivialisation of the subject matter. On the contrary, it suggests the deftness of movement required as we navigate, albeit, at times awkwardly and anxiously, attempts to reconcile our concerns as educators with the prevailing discursive terrain that regulates much of what we do and how we do it. In relation to our disciplinary backgrounds in cultural studies, we see this as an important discussion, one that must be understood in the context of institutional power, the politics of identity and of the overarching discourses of neoliberalism.

—FINDING THE RHYTHM: POLICY, PERFORMANCE AND PRACTICE

The Bradley Report's authors outline the vision for national higher education to 2020. They argue that to realise this vision, 'A streamlined system with clearer roles for the Australian and state and territory governments, greater and fairer choice, more effective regulation and greater flexibility of provision is needed.'2 While not prescribing any formal restructuring processes as such, the report panel develop a narrative of progressive institutional policies that mobilises the language of neoliberalist discourse. To be successful in attracting government funding, institutions are advised to foster innovative cultures that are nevertheless regulated at a semantic level by words such as 'accountability', 'competiveness' and 'performance indicators', and at the policy level by the economic imperatives of the national and international marketplace.

In key areas our home university has pre-empted some of the recommendations of the report: most notably with initiatives to provide access to higher education for equity students and those of 'low socio-economic status' from regional and remote areas through a network of access centres established in 2000, and through an Indigenous Centre, located on the central campus to provide support and mentoring for Indigenous students as well as delivering Indigenous studies 
subjects to the regional network. These are the areas in which we both work and where we have noted over the past few years growing tensions between imperatives to increase access for equity and Indigenous students, and seemingly irresolvable difficulties in sustaining programs that facilitate successful transition and retention in a higher education environment. We argue that, at least in part, some of these difficulties can be traced back to the increasing corporatisation of universities within the matrices of neoliberalist discourse and higher education management.

On one hand, the managerial language of the Bradley Report is a call for greater transparency of practice and draws on various regimes of surveillanceperformance indicators, external and internal audits and reviews-to measure and police accountability. On the other hand, and as other researchers have noted, this is a language economy that fosters a climate of distrust and suspicion and an urgency 'to be seen' to be compliant. ${ }^{3}$ Indeed, so much time can be spent benchmarking, organising and attending review meetings, writing applications for various awards and citations that signify the individual's capacity, and by extension the institution's capacity, for marketable excellence, that teaching academics can end up feeling as though they are players in scenes reminiscent of Fritz Lang's 1927 film Metropolis: workers only there to service the apparatus.

Stephen Ball effectively captures this scenario with his argument that the 'policy technologies' of higher education, with their attendant demands for 'performativity', create: 4

a culture and a mode of regulation that employs judgements, comparisons and displays as means of incentive, control, attrition and change-based on rewards and sanctions (both material and symbolic). The performances (of individual subjects or organizations) serve as measure of productivity or output, or displays of 'quality', or 'moments' of promotion or inspection. As such they stand for, encapsulate or represent the worth, quality or value of an individual or organization within a field of judgement. The issue of who controls the field of judgement is crucial. ${ }^{5}$

He suggests that rather than producing an integrated and sustainable teaching and learning environment, these regulating technologies too often result in 'spectacle, or game-playing, or cynical compliance': what he calls 'fabrications' comprised of the privileged signifiers sanctioned by an organisation. ${ }^{6}$ Pressures to be competitive, to 
identify and realise key performance indicators, to be constantly innovative, entrepreneurial and so on, comprise the apparatus-the policy technologies-still governing many of our professional lives in 2011. It is an idea that Colleen McGloin explores in relation to the cultural politics of teaching awards in an increasingly individualistic and competitive higher education climate. ${ }^{7}$

In the past fifteen years or so there has been a growing body of scholarly work that engages with higher education policy as discourse. Following the work of Michel Foucault, much of this work has set about examining the ways education policy language constitutes academic workers as subjects. Foucault expressed reservations about merely treating discourse 'as groups of signs (signifying elements referring to contents of representations)'. He insisted that any analysis should entail consideration of discourse as a set of practices 'that systematically form the objects of which they speak'. ${ }^{8}$ It is at this level that researchers such as Ball, Bronwyn Davies, Henry Giroux, Peter McLaren and others engage with policy as discourse through examining those practices that derive from the fusion of neoliberalist discourse and the language of higher education management. ${ }^{9}$ In various ways, all express concerns about the consequences of a free market fundamentalism that produces what McLaren calls the 'pedagogical unsaid', or hidden curriculum, that glosses over the embodied exigencies of teaching and learning while simultaneously miming a critical awareness of cultural diversity. We will return in more detail to the embodying nature of teaching and learning. For now, we want to note this as a framing device for discussing the to-ing and fro-ing we do in our teaching practice as we attempt to ascertain, acknowledge, relate to, and accommodate the multiple speaking positions of our students while negotiating our own positionalities within the ever-changing sociocultural rhythms of contemporary academic life.

Davies argues that any examination of this field must take place at the levels of both 'rationality' and 'desire':

It is not a choice between compliance and resistance, between colonizing and being colonized, between taking up the master narratives and resisting them. It is in our own existence, the terms of our existence, that we need to begin the work, together, of decomposing those elements of 
our world that make us, and our students, vulnerable to the latest

discourse and that inhibit conscience and limit consciousness. ${ }^{10}$

While acknowledging both the possibilities and constraints of engaging policy as discourse, Carol Bacchi nonetheless affirms that this is a productive line of interrogation precisely because it allows us to identify and think about the various ways that policy-as-discourse limits and permits what counts as intelligible speech in the context of proposed reforms. ${ }^{11}$

Of course, Foucault's work also provides ways to explore questions about how we as constituted subjects locate ourselves in relation to the policy technologies of our workplace: how we navigate what he calls the 'games of truth' governing our professional identities and our institutional practices. For Foucault this is serious business. The 'care of self' is intimately entwined with how we understand those regimes of 'truth' that recruit and govern us as subjects; in other words, those relationships of power that allow us to speak or keep us silent.12 These games of truth are not mere word play or semantic amusements for Foucault. Only through understanding how they shape the practices constitutive of self-formation, can we begin to reconstitute identity and subjectivity; begin to ask questions about how we govern and how we are governed. ${ }^{13}$ Or, as Michael Peters puts it, develop a greater awareness about 'the ethics of self-constitution' in relation to the wider discursive frameworks. ${ }^{14}$ Lew Zipin and Marie Brennan cover similar ground drawing on Pierre Bourdieu's notion of habitus to explore questions of how to renegotiate in ethical ways those policy initiatives that demand compliance at the cost of silence. They argue the necessity for a 'reflexive search for critical mindfulness-our own, and that of colleagues' as we go about our work as teachers, researchers and citizens in our workplaces. ${ }^{15}$

Alain Badiou provides another dimension in our search for an ethical practice of cultural competence, which complicates further our concern regarding compliant lip service to current conceptual models. Badiou critiques the 'mindless catechism' of ethics and its absorption by Western capitalism into a conservative consensus of human rights. He reminds us that in advocating for an ethical practice, we risk returning to the very model of neoliberalism we are undermining. ${ }^{16}$ Badiou calls for an 'ethics of truths', or of 'processes of truth, of the labour that brings some truths into the world'.17 
Although drawing on different theoretical frameworks and methodological approaches, the pressing issue at the heart of much research into higher education policy produced over these last fifteen years is how to work with policy as it shapes our practices, and how to do so ethically, substantively and truthfully. Perhaps these are old-fashioned terms, not in the spirit of much contemporary theoretical work in circulation, and we register the on-going philosophical challenges to them in the light of their absorption by contemporary discourses of neoliberalism. Nevertheless, they occupy an undeniable and compelling place in the concerns that exercise those who research in this area-as, indeed, they do for us in this article-and as such demand attention. What we are noting here are the seemingly irresolvable tensions that reside in the gap between practice and theory. It is these tensions that drive us to search for more satisfactory possibilities that might better 'choreograph' our movements through the contestatory terrain of our work lives, make us better educators, and provide the basis for a new language that resists the more reductive demands of corporate managerialism.

We worry that rather than fostering mindful responses shaped by the idea(l)s of social justice and equity central to the Bradley Report's recommendations, the kind of apparatus fostered by these conditions of practice can too often reduce impulses for academic innovation to a series of 'box ticking' exercises so radically disconnected from the business of credible practice that they merely conform to the letter of the recommendations and so stand in place of sustainable and ongoing implementation. In this climate, 'innovative' and 'competiveness' can be code for doing more with reduced funding and infrastructure or developing a model that looks good for the semester relevant to career progression and then falls by the wayside. As Christine Asmar and Susan Page point out, while recommending initiatives to increase Indigenous access to higher education and identifying the need for universities to develop cultural competence at curricula and staffing levels, the Bradley Report is surprisingly circumspect about how these aims are to be achieved. ${ }^{18}$ Asmar and Page argue that the national push to incorporate cultural competence into curricula and the wider higher education environment is too important an initiative to fall prey to a hasty and non-reflexive utility in the guise of considered compliance. They are concerned there are not enough Indigenous staff in the university system to adequately realise the initiative. 
We are concerned that the pressures to nevertheless comply will ultimately result in a model that falls significantly short of the intended outcome.

-'SAMPLING': THE RHYTHMS OF SOME MULTICULTURAL CLASSROOMS

Sample one

In a recent seminar for a 200-level Indigenous Studies subject, a light-skinned male student who publicly identified as Indigenous and was known to come from a financially comfortable middle-class family took issue with another student, the visibly non-Anglo daughter of Vietnamese 'boat people' who arrived in Australia in the early 1970s. In a tutorial where discussions focused around issues of colonial policy, the interchange between these students proceeded as follows:

Vietnamese Australian student: 'I understand what it's like to be marginalised and othered in this country. My parents came here on a boat with no English and worked so hard just so we could survive and I could have the benefit of an education.'

Indigenous student: 'All due respect, but you couldn't possibly understand what it's like to be Indigenous in this country.'

The unfortunate outcome of this silencing of the Vietnamese student's narrative resulted in her becoming noticeably distressed and leaving the room. Notwithstanding the gender relations at play, this interchange brings into view what we see as the dangerous hierarchies of suffering that result from the competing forces integral to the neoliberal discourses informing current models of cultural competence. We suggest, and indeed, the literature suggests to us, that cultural competence as it is marketed in many Australian contexts sets up hierarchies of difference whereby certain narratives override and, in many instances, silence others. Clearly, the Vietnamese student sought to relate, empathise and share her own knowledge of what it is like to be positioned as an 'outsider'. To be fair, the Indigenous student's response was respectful in tone; the problem is that the hierarchy of suffering was already in place: the Vietnamese student could not understand regardless of physical difference, because one culture took precedence in this context over another, and one set of histories assumed more suffering than another. 


\section{Sample two}

One of the authors was teaching a subject in Indigenous Studies. There were Indigenous students known to her in the course. Of the twenty-two students in the class, one was a black woman from Kenya. In an effort to apply and demonstrate an ethics of teaching that demonstrated inclusivity the teacher invited the student, when it became her turn, to give a class presentation that focused on her own culture. This was a successful exercise. The student was pleased to impart her knowledge and the class interested to receive it. A mutual interchange of teaching and learning occurred. However, towards the end of the presentation, the teacher noted the silence of an otherwise vocal Indigenous student who later confided that he found it difficult to say anything when a black person was speaking.

\section{Sample three}

In the university Indigenous Centre a computer lab is provided for use by Indigenous students. On a few occasions Asian students from a language college located within the university were seen working on the computers in the lab, probably when the computers in their lab were all in use. The international student language centre and the Indigenous Centre are immediately adjacent, sharing the same building. The international students were forcefully told by some Indigenous students that they could not use the Indigenous lab as "this is a "safe space" designated for Indigenous students only'.

\section{Sample four}

In a first-year Women's Studies subject comprised of domestic and international students from diverse cultural backgrounds, an Indigenous consultant was invited to speak with the class in a lecture format about Aboriginal histories and the Stolen Generations. Through a series of personal anecdotes the speaker, rather than drawing students into a deeper consideration and understanding of the catastrophic consequences of colonialism for Aboriginal peoples, made them feel directly responsible for the policies. Many of the international students-most from nonEnglish speaking backgrounds-shut down, unable to find a point of connection or to relate the anecdotes to the recommended readings for this section of the subject. A significant proportion of the students were young women from Islamic backgrounds, who felt so overwhelmed by the speaker's comments and 
observations that they were completely silenced, feeling unable to speak or write about this section of the subject; two withdrew from the subject.

These examples are but glimpses of the daily terrain of our teaching practices where current discourses of cultural competence do not fit with what we see and experience, and where the very idea of cultural 'competence' as it currently stands sets up its own binarisms that disarticulate the histories and narratives of certain students, rendering learning spaces safe for some and not others. These situations occur often enough to inspire us to consider possibilities for praxis where mindfulness of differential histories, beliefs and experiences can be in some way instituted without negating difference or resorting to essentialism. We are aware that this sounds somewhat utopian and reiterate that we see this article as a starting point for discussion rather than a prescription for alternative 'programs'. We are also cognizant that, in practice, there is a negotiation that occurs in each situation where any idea(l) of 'competency' is contingent on far more than current cultural competence programs can offer as packages for learning. In other words, if it is culturally sound or competent to understand the complex histories of Indigenous peoples in order to understand the specific needs of that group, then how do we, as educators, respond when we are faced with students who are not directly affected by that history and, because of the pervasiveness of the discourse, silence others as illustrated in the first example?

On the other hand, how do we ensure a speaking position for the silenced Indigenous student who feels she or he is not 'Indigenous enough' because she or he is light-skinned? And how do we teach Indigenous students that the colonial violence experienced by Indigenous people intersects with the appalling treatment of Chinese people during the early colonial period and continues to inform the antiAsian sentiment often expressed today? We are not making accusations of racism here, but noting how ideas of cultural safety are internalised as they are now played out in public spaces in ways that exclude difference, precisely as they purport to be inclusive. At the core of our inquiry are two central questions: how do we effectively negotiate (with a view to deconstructing) the hierarchy of cultures that is set in place through cultural competence programs; and how do we do this and also locate a speaking position for ourselves? Specifically, how do we heed the call for greater cultural competence in the multicultural environment of the Australian university 
system? How, as non-Indigenous academics, can we best respond effectively to the Bradley Report's finding on access, retention and success for Indigenous students without resorting to a 'box ticking' response to a complex and urgent issue?

—CULTURAL COMPETENCE: WHAT IS IT ALL ABOUT?

The term 'competence' derives from the Latin competentia which translates as expertise. This definition raises the question: how does one acquire cultural expertise? And, if one can, how does such an attribute translate across the multiple sites and contexts comprised in our teaching? In order to tease out what cultural competence means in its current manifestation in the Australian university system, and to consider how it might exceed the limitations of its neoliberal preoccupations to acquire some usefulness in addressing institutionalised racism, we need firstly to briefly outline the terrain.

The term has acquired considerable currency in recent years. Mark Furlong and Rhonda Brown observe in their critique that its status is positive. ${ }^{19}$ It is a discourse complementary to multiculturalism and similarly underscored by regard for undifferentiated notions of respect for all cultures. Cultural competence in its varying forms has permeated all cultural institutions including mainstream media. However, most work in this area constitutes a wholesale deference to an idea that neither acknowledges nor engages with its tensions and contradictions or, indeed, its application to both educators and students. We therefore believe that cultural competence operates as a kind of transcendental signifier that regulates all institutional sites through programs that 'teach' respect for difference, often in ways that conform to the precepts of managerialism; that is, through brief courses that by virtue of their brevity generalise and essentialise the complexity of cultural differences.

In this context, cultural competence assumes a 'knowing' beyond dispute or detraction, as exemplified in a recently circulated email to university staff from Universities Australia, the national peak organisation representing Australia's universities:

Universities Australia has signed a funding agreement with the Commonwealth for a $\$ 500,000$ Indigenous Cultural Competence in Australian Universities program. This program has been developed jointly 
by Universities Australia and the Indigenous Higher Education Advisory

Council.20

The Universities Australia website describes Indigenous cultural competence as: 'the ability to understand and value Indigenous perspectives and provides the basis upon which Indigenous and non-Indigenous Australians may engage positively in a spirit of mutual respect and reconciliation'.21

From our standpoint as educators of Indigenous, domestic and international students, we want to challenge corporatised and reductive notions that suggest one can 'know', and thus become proficient in cultural difference, through programs that 'teach' cultural respect. We argue that in its current form, cultural competence, ostensibly (theoretically) a potentially useful framework for observing mindfulness and respect, is a discourse that establishes a 'sameness' among culturesparadoxically, as it seeks to recognise difference from within. As a discourse that attracts a seemingly wholesale endorsement across many institutional sites, cultural competence can act censorially to stifle or shut down debate. The classroom samples indicate that cultural competence can also be applied to one culture at the expense of another, and can assume a blanket disadvantage for students of a particular cultural background.

It is necessary here to also acknowledge the materiality of 'cultural competence' as a known, recognised, authorised and normalised set of practices within many cultural institutions. As Nicholas Burbules argues:

whenever any pedagogical practice or relation becomes 'naturalized' and comes to be seen as the only possibility, the best possibility or the most 'politically correct' possibility, it becomes (ironically) an impediment to human freedom, diversity, exploration, and-therefore-the possibilities of learning and discovery. ${ }^{22}$

Proceeding from this idea, the following discussion examines current concepts of cultural competence and its implications for pedagogical practice.

The reader will note we are speaking of cultural competence in general terms and not denoting its specificity in our own work environs as 'Indigenous cultural competence'. This is because we are challenging the idea of cultural competence in its broadest configuration as an ethical concept that can seamlessly transfer to practice through brief educational courses. It is not, therefore, the 
'Indigenous' aspect of cultural knowledge or ethics we take issue with, but the idea and practice of any concept that is dedicated to one category, group of people or culture. As educators in diverse contexts, it is the omission of other classificatory elements that is of concern. We also refer generally to 'cultural competence' as this is how the literature refers to the concept.

There are a multitude of definitions describing what constitutes cultural competence, most of which derive from health care literature and many of which use terms such as 'knowledge based skills', 'organisational awareness', 'effective service delivery', 'diversity training', 'ethno-specific training', and so on. The literature on cultural competence is broad. There is a cultural competence website that explains precisely what is needed to become competent across a diverse range of institutional sites. It provides information about how to 'value diversity' and how to 'maintain objectivity when faced with difference'.23 The website's prescription for attaining cultural competence bears mention: it typifies the literature in general, and particularly as it applies both to health and education. The site proffers 'five essential elements that contribute to a system's ability to become more culturally competent'. It goes on to assert:

The system should:

- value diversity;

- have the capacity for cultural self-assessment;

- be conscious of the 'dynamics' inherent when cultures interact;

- institutionalize cultural knowledge; and

- develop adaptations to service delivery reflecting an understanding of diversity between and within cultures.

Further, these five elements must be manifested in every level of the service delivery system. They should be reflected in attitudes, structures, policies, and services. ${ }^{24}$

These principles are reiterated, expanding on their specificity for Indigenous education, in Principles and Practices of Cultural Competency: A Review of the Literature. The author of this document, prepared for the Indigenous Higher Education Advisory Council (IHEAC), draws on an almost ubiquitous definition of cultural competence: 'congruent behaviours, attitudes and policies that come together in a system, agency, or among professionals and enable that system, 
agency, or those professionals to work effectively in cross-cultural situations'. ${ }^{25}$ The document further defines cultural competence as 'the ability to engage in actions or create conditions that maximise the optimal development of a client and client systems'. It argues that cultural competency demands 'awareness, knowledge, and skills needed to function effectively in a pluralistic democratic society'. ${ }^{26}$ We will not labour here. Suffice to say that most of the literature is replete with the platitudes of fairness, equity and social justice artfully mapped onto the managerial lexicon of 'systems', 'processes', 'clients' and 'services'.

In the interests of the regulative, yet seemingly invisible, politics that inform policies pertaining to cultural expertise, we now consider how the current discourse of cultural competence displaces a pre-existing and, in our view, very real concern at universities about racism often publicly ridiculed under the rubric of 'political correctness'. Cultural competence, we argue, in its current packaged form is a diluted affectation of mindfulness about what is said and done by white, nonIndigenous subjects. In other words, in its current state, the discourse centralises white subjects as in need of instruction to become more competent in their dealings with Indigenous cultures. Because of this, its application can silence other expressions or articulations of discrimination that take place in a classroom.

—Locating THE PARAMETERS OF THE CURRENT MODEL

Where once the catchcry of political correctness served to silence discussion about race and racism, we now have a language around 'competence' that speaks of 'safety', 'appropriateness', 'sensitivity' and so on. It portends to 'open up' the airwaves as it simultaneously limits the field of inquiry. The limitations are locked into the language of the discourse; if we are seen to be 'attending' to difference through regulated programs that assure 'outcomes', there is no particular need to keep asking what difference is: it just is. The discourse, shaped by neoliberalism's preoccupations with 'outcomes', plays out in deterministic ways; non-Indigenous subjects focus on a particular cultural group at the expense of the many subjectivities that make up our student cohort. Embedded into the discourse as that which we now 'know', in Foucauldian terms, as an 'object of knowledge', cultural difference assumes something we (white folks) do not have and need to acquire in order to satisfy the requirements of cultural competency. 
The discourse gives primacy to culture and obliterates other, messy, signifiers such as class, sexuality and gender that might threaten to destabilise programs designed to teach cultural competence as a shared set of Indigenous histories, struggles and practices. The discourse relies for its coherence on a universality of Indigeneity that excises difference from within and between Indigenous cultures. Prior to colonisation, there were over two-hundred-and-fifty Indigenous language groups in Australia, forming separate nations identified both linguistically and culturally through a diverse range of rituals and practices. Given this history, we identify in the pedagogy of cultural competence a monolithic approach to teaching respect and awareness that neither recognises nor accommodates the historical or cultural diversity of Indigenous peoples. Nor does it speak to the vast range of cultural differences between and among many of our Indigenous students who are from urban areas but whose histories and experiences cannot be neatly encapsulated into a single module of learning for the purpose of making 'competent' its mainly non-Indigenous participants.

Teaching in contexts where Indigenous and international students of many cultural backgrounds form a large part of our student cohort, the implications of a 'blanket' approach to issues of race neatly wrapped in some marketed program erase the very issues our teaching seeks to foreground: the actual lived realities of difference whose representations have not altered to relieve racism in any significant way since the advent of 'cultural competence'. Because we deal directly with the layering and complexity of cultural diversity and, in many cases, its attendant hierarchies of suffering, we find it at times impossible to mark out a speaking position for ourselves: we are effectively 'tarnished' by the discourse that positions us as only white and, according to National Indigenous Higher Education Network (Australia) (NIHEN) determinations, necessarily in need of 'training':

professional development opportunities in CC and Indigenous Studies should be provided for all non-Indigenous staff members so that Indigenous issues can be appropriately addressed in the units they teach.27 Let us state emphatically that we do not object to being trained to alleviate racism, bigotry or any other expression of prejudice we come across in our work. And we are not so arrogant as to claim exemption from discourses of racism in our own lives. The problem as we see it is not the idea of cultural competence programs per 
se, but the way cultural competence has been taken up as a 'truth' that cannot be challenged without fear of accusation. As we have noted, with deference to Jacques Derrida, it has become a transcendental signifier marked by a metaphysics of presence: a truth whose meaning obscures all other signs. ${ }^{28}$

—CULtURAL COMPETENCE: SIDE-STEPPING THE ISSUE?

Indigenous students from urban environments-and particularly from the region where we teach-are often not 'marked' by visible signifiers of Indigeneity. They express culture in a multitude of ways: some proudly, some tentatively, some even silently. Indeed, we have both taught in class situations where Indigenous scholars have remained anonymous throughout an entire course. There are various reasons for this, including that, for many Indigenous students, publicly identifying their Indigeneity tends to position them as 'experts' on all matters Indigenous by other students and, in some cases, by non-Indigenous teachers. This kind of positioning often comes from a desire to be respectful and to defer to what is assumed 'authentic' knowledge and experience. Being noted as the 'expert' can be daunting, especially for Indigenous students who have only recently begun to find out about their heritage or identify as Indigenous, and who have enrolled in Indigenous Studies as a way of learning more. Certainly, we teach many Indigenous students who have very little knowledge of the history of Australian colonisation. Not only are assumptions made about Indigenous students and certain types of knowledge or cultural credibility, the discourse of cultural competence, as it is marketed in many public arenas and institutions, also assures that all Indigenous people are marked by historical disadvantage.

Our university, like many others, has initiated a cultural competence program. Currently, it takes the form of two three-hour seminars that introduce participants to Indigenous culture. Such programs also run in the wider community, in private corporations and government departments and, in particular, in health organisations. We are advised that the sudden interest in such programs is 'riding a wave' following the official apology to Indigenous people by the Rudd Labor government in February 2008. ${ }^{29}$ Bronwyn Lumby and Terri Farrelly, who are involved in cultural competence training (CCT) assert that despite its popularity as a means to achieving culturally appropriate service delivery, 'there has been relatively 
little systematic evaluation of its potential impact'.30 What we find unnerving is the acknowledgement by some of our Indigenous colleagues that cultural competence is 'flavour of the month' and that it has a 'shelf life'. If this is the case, any conceptualisation of race relations that speaks to contemporary social experiences can only be conceived of as a response to current neoliberal ideologies.

Cultural competence as knowledge that can be learned through a module or lesson plan echoes Paulo Freire's concept of banking education where students are empty vessels to be filled with knowledge deemed desirable by prevailing discourses. ${ }^{31}$ The 'chunk' of knowledge, once imparted, acts as a guarantor that one will be always proficient and ethical in one's dealings with other cultures and that at most a refresher course may be required to fill in the gaps. Cultural competence courses, unless critically formulated, presuppose and imply a fixed set of knowledges. In their current application at most institutional sites, they are structured around content that deconstructs its own stated logic of difference. As a form of public pedagogy, cultural competence courses absorb difference by virtue of their temporal and spatial application; courses run to a maximum of six hours and are conducted within institutional spaces. It is through the specificity of this spatio/temporal application that we can begin to identify the institutional power relations that are seen to be addressing racism as they simultaneously level cultural and racial difference.

Henry Giroux tells us that 'pedagogy is not merely about uncovering what is there'. ${ }^{32}$ It is a process that takes its cue from the idea that knowledge is subject to historical change and to the new information that accompanies change through struggle, conflict, contestation and consensus. Offering a group of non-Indigenous people a 'crash course' in the history of colonisation, its violence and the attendant policies that continue to cause suffering to Indigenous peoples, does not address the institutional asymmetries of power that structure the implementation of such courses: universities have a long history of supporting and contributing to colonial discourses. The argument often espoused is that something is better than nothing, and that some form of learning about Australia's colonial history will serve a purpose. However, our teaching tells us this is not necessarily the case.

The classroom samples outlined earlier indicate the varying degrees of immobilising guilt that can accompany such knowledge when time constraints do 
not allow the luxury of nuance or debrief; students are often shocked when they undertake Indigenous Studies to discover the level of brutality associated with colonial conquest. Domestic students have often relayed their disbelief at 'finding out' and their anger at not being taught prior to university study about the various policies that regulate(d) the lives of Indigenous peoples. From international students, the comment, 'you treat your Indigenous people very badly' is common and inadvertently sets up its own hierarchy of racisms that can see students feeling varying levels of comfort (in not being Australian) or discomfort (in being Australian). When we include in our teaching the multiple layers of colonial experience endured by convicts, women, Irish, Chinese and Pacific Island labourers, the history of race relations in Australia reveals its complexity. Small chunks of untheorised knowledge can have adverse affects, and as a pedagogical practice this form of teaching and learning does nothing to address the causes-or effects- of institutional racisms in any coherent way. We pluralise this term because discriminatory expression and (in)competency in areas of human interaction is itself a heterogeneous force and cannot be neatly conceptualised according to physicality, differences in cultural practice or, indeed, whiteness, as the sole causality of racism. As Lumby notes of cultural competence training, 'currently most training sessions rely on the usual formula white=racist, black=disadvantaged and while this continues nothing will change'.33

This brings us to a discussion about the body of knowledge called 'whiteness studies' and its application in our own praxis. We are somewhat hesitant in addressing this topic as we perceive it has also become an orthodoxy whereby the 'privilege of whiteness' has been so inextricably woven into our pedagogical arena such that non-adherence to its authority can incur penalties. For one author, this took the form of a strong suggestion that a recently submitted journal paper look at the literature on whiteness despite this not being central to the paper's focus. Without question, whiteness studies has produced work that is a contributing force to teaching anti-racism and to alerting white subjects to the need for reflexivity. However, our conversation is inspired by our position as white women of a certain age and class background who teach across multiple sites and contexts: we are not only identified by white skin. And while we seemingly 'fit' into the category of 'white 
race privilege', as suggested elsewhere, ${ }^{34}$ our subjectivities are marked, and our speaking positions informed, by a range of other signifiers and histories.

We are acutely aware of the way that whiteness constitutes Western epistemology and do not resile from the privilege of our positions within the most elite of Western institutions. ${ }^{35}$ Neither do we wish to embark on personal accounts of our subjective markers for the purpose of setting up (yet another) hierarchy that will legitimate a speaking position for us. Rather, we write from a position of reflexivity in pursuit of exploring what we see as the pitfalls of the equation, 'white=racist, black=disadvantaged' which underpins the discourse of cultural competence and allows the proliferation of racist practice within institutions to go unnoticed. If the formula works as a pedagogical recipe for consumption, why complicate it with a critical theory of racism?

\section{-FINDING A NEW STEP}

Complicating cultural competence, we contend, is at the heart of locating a more meaningful way of teaching across multiple sites and contexts. In returning to our dilemma, then, let us further problematise the terrain by thinking through the embodied nature of pedagogy and considering the role of the body in developing an ethical pedagogical praxis. We want to consider how a change in thinking might manifest corporeally as we 'move' across classroom spaces finding ways of engaging the student body, individually and collectively. At the core of cultural competence are differences that can be understood, if not always recognised, in their embodied form: students who are Indigenous, white, black, Asian, domestic, American, Jewish, Muslim, homosexual, lesbian, working-class, disabled, middle-class and so on, need to be 'seen' as corporeal entities who observe, feel and experience the world in different ways that can be articulated and responded to, and, indeed, because of their differences, can contribute significantly to the teaching and learning process. So it is in our interests to read these embodied sites of teaching and learning, to seek out their inscriptions and cultural narratives. Cultural competence as an ethical practice, it could be argued, invites us to see bodies in the Bakhtinian sense as utterances that take up 'a particular definite position in a given sphere of communication'. Bakhtin tells us 'it is impossible to determine its position without correlating it with other 
positions. ${ }^{36}$ The body, in this schema, cannot be disarticulated or detached from its associated signifiers.

It is at this point that we can begin to destabilise the homogenising impulses of cultural competence and promote a broader conceptualisation of what it means to be competent in a cultural sense. In arguing for recognition of the embodied reality of pedagogical sites, we can begin to understand the body's engagement with, or responses to, other bodies. Contemplating the corporeality of pedagogical praxis, our own and our students', inspires us as feminists, and also as educators, to consider the power relations that organise teaching and learning around the discourses we challenge here. These discourses often attempt to position us as inadequately equipped to effectively and ethically provide safe experiences for all our students. Understanding the embodied nature of classrooms allows us to consider also the production of knowledge in different ways: we become more conscious of performativity, of the 'props' we use as pedagogical aids and of the ways that students also perform learning through body language, eye contact, facial expression and movements that suggest interest, disinterest, agreement or contestation. Spatial energy can be evaluated through giving some primacy to substance and matter. This is a useful adjunct when teaching anti-racism as tensions arise frequently and reading the source of tension can be imperative to any articulation of cultural competence. Let us not assume, though, that reading the embodied classroom will provide us with all we need to know about cultural differences or, indeed, that our readings will always be accurate. It is crucial that we understand the relationship between embodiment in pedagogical terms and discourse, between the physicality of teaching and learning with its multiple inscriptions and the discourses that 'move' it, energise it, organise it and render it less awkward and more agile.

\section{-CONCLUSION}

We have expressed some of our concerns about cultural competence and shared our experiences in trying to maintain an ethical, truthful and substantive praxis while acknowledging the shifting significations of these terms, and their potential for assimilation into the managerial discourses informing neoliberalism. With this article we hope to initiate a dialogue that incorporates experience, reflections and 
concerns with current literature and various theoretical approaches to the debate. As well as soliciting dialogue, our research leads us to conclude that further work is necessary if we are to address in any meaningful way the increasing diversity of university student cohorts. In opening up spaces where we can identify the corporeal nature and effects of pedagogy, in the university and in public spaces where policy is shaped, we hope to extend the dance metaphor. Following Susan Bordo's claim that 'the appreciation of difference requires the acknowledgement of some limit to the dance, beyond which the dancer cannot go', we consider her justification for this claim: 'If she were able to go there, there would be no difference, nothing which eludes.' ${ }^{37}$ We suggest, however, that there are other steps we can take and that it is in our and our students' interests that we continue this dialogue, this 'dance'.

Colleen McGloin is a senior lecturer in the Faculty of Arts, University of Wollongong. Her current research interests are in critical theory, and feminist approaches to pedagogy and higher education. She has taught literature, communications and cultural studies, and currently teaches in the area of Indigenous studies.

Jeannette Stirling is a senior lecturer at the University of Wollongong. Her abiding research interests are in those intersections between policy, practice and institutional cultures. Jeannette has taught academic and professional writing, Australian history, Australian literature, communication and cultural studies, and nursing.

\footnotetext{
-NOTES

1 Denise Bradley et al., Review of Australian Education: Final Report, Australian Government, Canberra, 2008, <www.deewr.gov.au/he_review_finalreport> (accessed 3 March 2009).

2 Bradley et al., Review of Australian Education, p. 1.

3 See, for example, Walter Humes, 'The Discourse of Educational Management', Journal of Educational

Enquiry, vol. 1, no. 1, 2000, pp. 35-53; Bronwyn Davies, 'The (Im)possibility of Intellectual Work in
} 
Neoliberal Regimes', Discourse: Studies in the Cultural Politics of Education, vol. 26, no. 1, 2005, pp. 114; Bronwyn Davies, Michael Gottsche and Peter Bansel, 'The Rise and Fall of the Neoliberal University', European Journal of Education, vol. 41, no. 2, 2006, pp. 305-19; Alison Phipps, "The Sound of Higher Education: Sensuous Epistemologies and the Mess of Knowing', London Review of Education, vol. 5, no. 1, 2007, pp. 1-13.

4 Ball's particular use of the term 'performativity' refers to an exaggerated performance of identity instigated and controlled by the policy technologies governing the workplace. He argues that the 'costs' of these technologies include 'institutional schizophrenia' and, for individuals, a kind of 'values schizophrenia', Stephen J. Ball, 'The Teacher's Soul and the Terrors of Performativity', Journal of Education Policy, vol. 18, no. 2, 2003, p. 221. His use of the term has interesting and potentially productive resonances with Judith Butler's notion of performativity as deriving from discourse's power to construct the very subjectivity that it defines and regulates.

5 Ball, p. 216.

6 Ball, p. 222.

7 Colleen McGloin, 'Recontextualising the Award: Developing a Critical Pedagogy in Indigenous Studies', International Journal of Humanities, vol. 6, no. 4, 2008, pp. 81-8.

8 Michel Foucault, The Archaeology of Knowledge and The Discourse on Language, trans. A.M. Sheridan Smith, Pantheon, New York, 1972 [1969], p. 49.

${ }^{9}$ For example: Ball; Davies; Davies et al.; Stanley Aronowitz and Henry A. Giroux, Education Still Under Seige, second edition, Bergin \& Garvey, CT, 1993; Henry A. Giroux and Kostas Myrsiades (eds), Beyond the Corporate University: Culture and Pedagogy in the New Millennium, Rowman \& Littlefield, Lanham, Md., 2001; Stanley Aronowitz, The Knowledge Factory, Beacon Press, Cambridge, Mass., 2000; Maxine Greene, 'In Search of a Critical Pedagogy', in A. Darder, M. Baltodano and R. D. Torres (eds), The Critical Pedagogy Reader, Routledge, London, 2003, pp. 97-112; Peter McLaren, 'Revolutionary Pedagogy in Post-Revolutionary Times: Rethinking the Political Economy of Critical Education', in A. Darder, M. Baltodano and R.D. Torres (eds), The Critical Pedagogy Reader, Routledge, London, 2003, pp. 151-84. 10 Davies, p. 13.

${ }^{11}$ Carol Bacchi, 'Policy as Discourse: What Does it Mean? Where Does it Get Us?', Discourse, vol. 21, no. 1, 2000, pp. 45-57, 49,

<http://search.informit.com.au.ezproxy.uow.edu.au/fullText;dn=102032;res=AEIPT>.

12 Michel Foucault, The History of Sexuality Volume 3, The Care of Self, trans. Robert Hurley, Pantheon, New York, 1984 (1986 ed.).

13 Jeannette Stirling and Alisa Percy, 'Truth Games/Truth Claims', in Stephen Milnes with Gail Craswell, Valli Rao, Annie Bartlett (eds), Critiquing and Reflecting: LAS Profession and Practice, Australian National University Press, Canberra, 2005, pp. 177-87.

14 Michael A. Peters, 'Educational Research: “Games of Truth” and the Ethics of Subjectivity', Journal of Educational Enquiry, vol. 5, no. 2, 2004, pp. 50-63, 57. See also, Michael A. Peters, 'Truth-telling as an 
Educational Practice of the Self: Foucault, Parrhesia and the Ethics of Subjectivity', Oxford Review of Education, vol. 29, no. 2, 2003, pp. 207-23.

15 Lew Zipin and Marie Brennan, 'The Suppression of Ethical Dispositions through Managerial Governmentality: A Habitus Crisis in Australian Higher Education', International Journal of Leadership in Education, vol. 6, no. 4, 2003, pp. 351-70, 369.

16 Alain Badiou, Ethics: An Essay on the Understanding of Evil, trans. Peter Hallward, Verso, London, 2001.

17 Badiou, p. 28.

18 Christine Asmar and Susan Page, 'Sharing the Load', Campus Review, 2009.

<http://www.campusreview.com.au/pages/section/article.php?s=Comment\&idArticle=13204>.

19 Mark Furlong and Rhonda Brown, "The Goal of "Cultural Competence": Contesting the Premise that Technical Skills should be Privileged Above “Culturally Critical Practice”', Psychology and Indigenous Australians: Teaching, Practice and Theory, Proceedings of the Second Annual Conference, UNISA, July, 2008, pp. 83-93.

20 Universities Australia, 2009,

<http://www.universitiesaustralia.edu.au/content.asp?page=/about/pos_vacant/index.htm>.

21 Universities Australia.

22 Nicholas C. Burbules, 'The Limits of Dialogue as a Critical Pedagogy' in Peter Pericles Triofonas (ed.), Revolutionary Pedagogies, Routledge, New York, 2000, pp. 251-73, 266.

23 Mark A. King, Anthony Sims and David Osher, 'How is Cultural Competence Integrated in Education?', 2009, <http://cecp.air.org/cultural/Q_integrated.htm>.

$24<$ http://cecp.air.org/cultural/Q_integrated.htm>.

25 T. Cross, B. Bazron, K. Dennis and M. Isaacs cited in Ellen Grote (ed.), Principles and Practices of Cultural Competency: A Review of the Literature, Indigenous Higher Education Advisory Council (IHEAC), August 2008, pp. 1-52, 14, <www.dest.gov.au/.../Principle_Practices_Cultural_Competencypdf.htm>.

26 <http://cecp.air.org/cultural/Q_integrated.htm>

27 Grote, p. 43.

28 Jacques Derrida, Of Grammatology, trans. Gayatri Chakravorty Spivak, Johns Hopkins University Press, Baltimore, 1974, p. 49.

29 Personal communication with Indigenous colleagues involved in cultural awareness/competence.

30 Bronwyn Lumby and Terri Farrelly, Family Violence, Help-Seeking and the Close-Knit Aboriginal Community: Lessons for Mainstream Service Provision, Australian Domestic and Family Violence Clearing House, UNSW, Sydney, 2009. Lumby and Farrelly head the Centre for Cultural Competence in Australia (CCCA). They present Aboriginal and Torres Strait Islander cultural competency training to a wide range of organisations throughout Australia. CCCA has been accredited and approved by TAFE 
and other government and non government bodies: see www.ccca.com.au $\langle\underline{\text { http://www.ccca.com.au/ }>}$ for details.

31 Paulo Freire, Pedagogy of the Oppressed, Continuum, New York, 2006, pp. 71-86.

32Giroux, p. 203.

${ }^{33}$ Personal email communication with Bronwyn Lumby, 6 October 2009.

${ }^{34}$ Colleen McGloin, 'Considering the Work of Martin Nakata's "Cultural Interface": A Reflection on Theory and Practice by a Non-Indigenous Academic', Australian Journal of Indigenous Education, vol. 38, Supplement, 2009.

35 Aileen Moreton-Robinson (ed.), Whitening Race, Aboriginal Studies Press, Canberra, 2005, p. 75.

36 Mikhail M. Bakhtin, Speech Genres and Other Late Essays, eds Caryl Emerson and Michael Holquist, trans. Vern W. McGee, University of Texas Press, Austin, 1986, p. 91.

${ }^{37}$ Susan Bordo, 'Feminism, Postmodernism and Gender-Scepticism', in Linda J. Nicholson (ed.), Feminism/Postmodernism, Routledge, New York, 1990, p. 145. 